\title{
Dorsal instrumentation with and without vertebral body replacement in patients with thoracolumbar osteoporotic fractures shows comparable outcome measures
}

\author{
Maximilian Schwendner ${ }^{1,2} \cdot$ Stefan Motov $^{3} \cdot$ Yu-Mi Ryang ${ }^{4} \cdot$ Bernhard Meyer $^{1} \cdot$ Sandro M. Krieg $^{1,2}$ (I)
}

Received: 7 March 2021 / Revised: 23 August 2021 / Accepted: 19 October 2021 / Published online: 5 November 2021

(c) The Author(s) 2021

\begin{abstract}
Purpose In the surgical treatment of osteoporotic spine fractures, there is no clear recommendation, which treatment is best for the individual patient with vertebra plana and/or neurological deficit requiring instrumentation. The aim of this study was to evaluate clinical and radiological outcomes after dorsal or $360^{\circ}$ instrumentation of osteoporotic fractures of the thoracolumbar spine in a cohort of patients representing clinical reality.

Methods A total of 116 consecutive patients were operated on between 2008 and 2020. Inclusion criteria were osteoporotic fracture, thoracolumbar location, and dorsal instrumentation. In 79 cases, vertebral body replacement (VBR) was performed additionally. Patient outcomes including complications, EQ-5D at follow-up, and sagittal correction were analyzed.

Results Medical and surgical complications occurred in 59.5\% of patients with $360^{\circ}$ instrumentation compared to $64.9 \%$ of patients with dorsal instrumentation only $(p=0.684)$. Dorsal instrumentation plus VBR resulted in a sagittal correction of $9.3 \pm 7.4^{\circ}\left(0.1-31.6^{\circ}\right)$ compared to $6.0 \pm 5.6^{\circ}\left(0.2-22.8^{\circ}\right)$ after dorsal instrumentation only, respectively $(p=0.0065)$. EQ-5D was completed by 79 patients after $4.00 \pm 2.88$ years $(0.1-11.8$ years) and was $0.56 \pm 0.32(-0.21-1.00)$ for VBR compared to $0.56 \pm 0.34(-0.08-1.00)$ without VBR after dorsal instrumentation $(p=0.994)$.

Conclusion $360^{\circ}$ instrumentation represents a legitimate surgical technique with no additional morbidity even for the elderly and multimorbid osteoporotic population. Particularly, if sufficient long-term construct stability is in doubt or ventral stenosis is present, there is no need to abstain from additional ventral reinforcement and decompression.
\end{abstract}

Keywords Osteoporosis $\cdot$ Osteoporotic fracture $\cdot 360^{\circ}$ instrumentation $\cdot$ Dorsal instrumentation

\section{List of Symbols}

ASA-PS American society of anaesthesiologists physical status

BMD Bone mineral density

CT Computed tomography
DGOU German society for orthopaedics and trauma

EQ-5D European quality of life-5 dimensions

OF Osteoporotic fracture

PMMA Polymethyl methacrylate

VAS Visual analogue scale

VBR Vertebral body replacement

Maximilian Schwendner and Stefan Motov have contributed equally.

Sandro M. Krieg

Sandro.Krieg@tum.de

Maximilian Schwendner

Maximilian.Schwendner@tum.de

Stefan Motov

stefan.motov@uk-augsburg.de

Yu-Mi Ryang

Yu-Mi.Ryang@helios-gesundheit.de

Bernhard Meyer

Bernhard.Meyer@tum.de
1 Department of Neurosurgery, Klinikum Rechts Der Isar, Technische Universität München, Ismaninger Str. 22, 81675 Munich, Germany

2 TUM Neuroimaging Center, School of Medicine, Klinikum Rechts Der Isar, Technical University of Munich, Munich, Germany

3 Department of Neurosurgery, Universitätsklinikum Augsburg, Stenglinstr. 2, 86156 Augsburg, Germany

4 Department of Neurosurgery, Helios Klinikum Berlin-Buch, Schwanebecker Chaussee 50, 13125 Berlin, Germany 


\section{Introduction}

Osteoporosis is a systemic disease characterized by reduced bone mass and disruption of bone architecture, resulting in an increased risk of fragility fractures which represent the main clinical consequence of the disease $[1,2]$. Fragility fractures of the spine are associated with substantial pain and suffering, disability, and even death due to cardiopulmonary complications [3]. The economic burden of incident and prior fragility fractures (mainly hip and vertebral fractures but also fractures of the pelvis, rib, humerus, tibia, fibula, clavicle, scapula, sternum, and other femoral fractures) in the EU was estimated at $€$ 37 billion, and costs are expected to increase by $25 \%$ in 2025 [4]. Osteoporotic vertebral fractures affect approximately $25 \%$ of all postmenopausal women and older men aged $>70$ years $[5,6]$. Most osteoporotic vertebral fractures are treated conservatively with bed rest, analgesics, bracing, early rehabilitation, and osteoporosis treatment with bisphosphonates [7, 8]. However, in some patients the fracture healing is impaired, leading to major complications such as pseudarthrosis, final vertebral collapse, spinal deformity, and spinal cord compression. Although these complications are rare, they are strongly related to poor prognosis, prolonged back pain, strong impairment of daily living activities, and reduced quality of life [9].

There have been considerable attempts to structure the process of decision-making for conservative versus surgical treatment in these patients, such as the osteoporotic fracture (OF) classification based on the work of the Spine Section of the German Society for Orthopaedics and Trauma (DGOU) [10]. While this is helpful for many cases and practitioners, a considerable number of cases end up in an ambiguous category, leaving it up to the surgeon to decide on the treatment strategy, especially if vertebrae plana or neurological deficit urges for instrumentation. In the case of surgical treatment, the surgical procedure of dorsal instrumentation with and without kyphoplasty as well as vertebral body replacement (VBR) is still neither structured nor supported with sufficient data. Particularly, biomechanical considerations such as restoration of the ventral spinal column with higher deformity correction rates have not been taken into account sufficiently in these classifications. Arguments against ventral reinforcement, such as calcified, and therefore completely rigid disks do also not hold up against our surgical experience of quite soft disks even when operating on considerably old patients. Furthermore, data on the role of fracture-related anterior spinal stenosis, location of the fracture in the junctional parts of the spine, or fracture-related neurological deficits are still scarce.

The aim of this study was to examine the clinical and radiological outcomes of patients with osteoporotic fractures of the thoracic and lumbar spine treated with or without a combined $360^{\circ}$ instrumentation based on the mentioned classifications as stratification.

By this, we do not intend to compare both approaches as competing options but, on the contrary, describe clinical reality in a large spine center mirroring various surgical approaches of different surgeons as it is the case all over the world.

\section{Methods}

\section{Hypothesis}

Our hypothesis is that if sufficient long-term construct stability is in doubt after dorsal instrumentation or ventral stenosis is present, additional ventral reinforcement and decompression via $360^{\circ}$ instrumentation are feasible and safe and offer a viable option.

\section{Ethics}

The study was approved by the local ethics board (registration number: 5022/11). We performed the study in accordance with the Declaration of Helsinki.

\section{Study protocol}

This study was performed in accordance with the STROBE statement. Patients with suspected osteoporosis on radiographs between 2008 and 2020 were considered eligible for this study and retrospectively examined. Inclusion criteria were patients undergoing dorsal instrumentation of the fractured spine with and without additional VBR at our institution. Subsequently, patients undergoing vertebroplasty only or conservative treatment were not included in this study. For all patients, the fractures were classified according to the $\mathrm{OF}$ classification and according to the $\mathrm{OF}$ classificationbased score by Blattert et al. [10, 11]. The OF classificationbased score by Blattert et al. was introduced in 2018 and is calculating a score based on the OF classification of the fracture, bone mineral density, existence of an ongoing fracture, pain levels, neurological deficits, mobilization under analgesia, and health status [11]. Perioperative complications requiring medical attention regarding further treatment and diagnostics were analyzed during the whole inpatient stay. A structured query in accordance with the European Quality of Life-5 Dimensions (EQ-5D) for Germany was performed for every patient in a phone call follow-up or regular follow-up in our outpatient department. 


\section{Surgical procedure}

Indications for the operative procedure were discussed at our neurosurgical department meeting consisting of seven experienced neurosurgeons with spinal focus. Surgical experience regarding indication and operative procedures was persistent over recruitment time. Dorsal instrumentation was routinely performed with navigated pedicle screws instrumentation: two segments above and two segments below the fractured vertebrae. No hooks or wires were implanted. In the case of additional VBR, surgery was performed via a lateral approach during the same index admission in. Therefore, the fractured vertebrae and adjacent vertebral disks were resected and anterior decompression was performed if spinal stenosis was present.

\section{Radiographic analysis}

For radiographic analysis, the anterior height and posterior height of the interspace between the lower endplate of the upper vertebrae and the upper endplate of the lower vertebrae of the fractured level were measured. Furthermore, the resulting angle between the upper endplate of the upper vertebrae and the upper endplate of the lower vertebrae of the fractured level in a sagittal view was acquired (Fig. 1). Measurements were taken on preoperative CT (computed tomography) scans and plain standing X-rays postoperatively. In cases with VBR, measurements were acquired preoperatively on CT scans, after dorsal instrumentation and after VBR on plain standing X-rays (Fig. 1).

\section{Data analysis}

Statistical analyses were performed using Prism (version 8.4.1; GraphPad Software, La Jolla, CA, USA). Descriptive statistics including mean, median, minimum, maximum, and standard deviation were calculated for patient- and fracturerelated characteristics including radiographic measurements.
Furthermore, cohorts treated with and without VBR were compared. Therefore, Mann-Whitney U tests for unpaired samples as well as Fisher's exact tests with a level of significance set at $p<0.05$ were performed.

\section{Results}

\section{Patient characteristics}

A consecutive series of 116 patients ( 83 women, 33 men) with 129 fractures of the thoracic and lumbar spine were analyzed. All patients underwent dorsal instrumentation. In 79 cases, VBR was performed additionally via a lateral retroperitoneal or transthoracic approach. No access surgeon was used. Gender and age distribution (74.0 \pm 8.6 (47.9-91.8) years with VBR vs. $75.4 \pm 11.2(48.8-92.4)$ years without VBR) were equal between both groups (Table 1). Risk factors were distributed similarly between both groups with a median ASA-PS (American Society of Anaesthesiologists physical status) class of $2(1-4)$ for $360^{\circ}$ instrumentation and $3(1-4)$ for dorsal instrumentation $(p=0.172$; Table 1$)$. The OF and OF classification-based score were $4(2-5)$ and 8 (2-15) for patients with VBR and $4(2-5)$ and 9 (4-12) for patients without VBR, respectively $(p=0.797 ; p=0.855$; Table 1). Main indications for surgical treatment were fracture-related spinal stenosis from anterior, which was present in 59 cases of patients with VBR and 19 cases without VBR, junctional location of the fracture (36 patients with VBR and 12 patients without VBR), vertebra plana (30 patients with VBR and 16 patients without VBR), and fracture-related neurological deficits (18 patients with VBR and 8 patients without VBR) (Table 1).

\section{Surgical data}

In $55.2 \%$ of cases, the most severe fracture according to the OF classification-based score was located in the lumbar
Fig. 1 Analysis of the fractured vertebral body. It illustrates the angle of the fractured vertebral body measured between the upper plate of the vertebral body above and the upper plate of the vertebral body below the fractured vertebra. The angle of the fractured vertebra was measured before $\mathbf{A}$ and after dorsal instrumentation $\mathbf{B}$ as well as after $360^{\circ}$ instrumentation $\mathbf{C}$

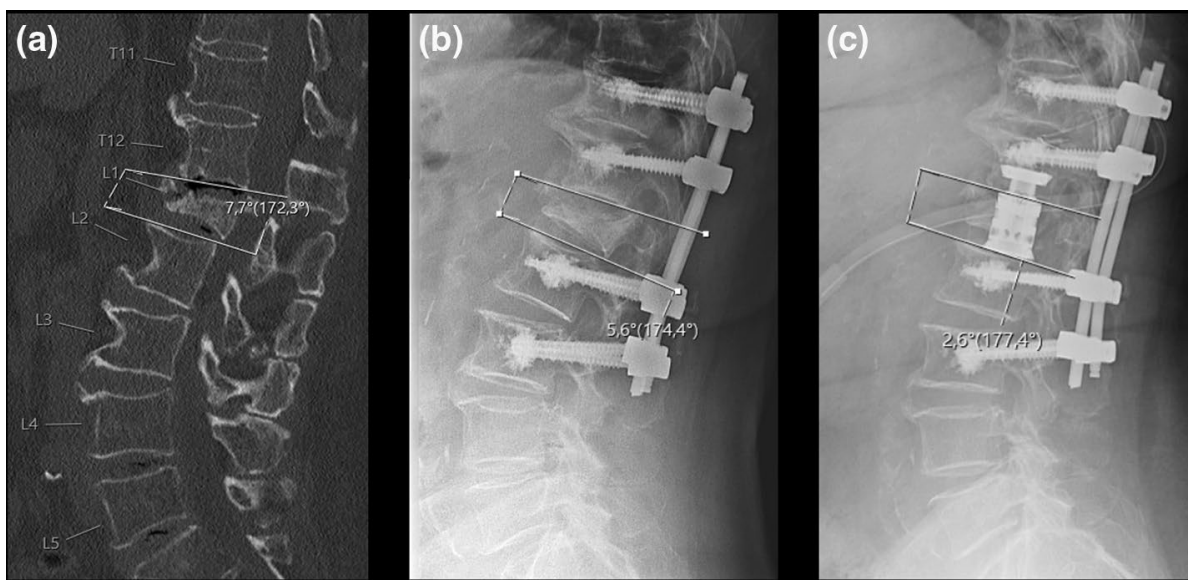


Table 1 Patient data and risk factors

\begin{tabular}{|c|c|c|c|}
\hline$n(\%)$ & $360^{\circ}$ instrumentation & Dorsal instrumentation & $p$ value \\
\hline Number of patients & $79(68.1)$ & $37(31.9)$ & - \\
\hline Female gender & $58(73.4)$ & $25(67.6)$ & 0.5166 \\
\hline Age at surgery $(y ;$ mean $\pm \mathrm{SD}$; range $)$ & $\begin{array}{l}74.0 \pm 8.6 \\
(47.9-91.8)\end{array}$ & $\begin{array}{l}75.4 \pm 11.2 \\
(48.8-92.4)\end{array}$ & 0.270 \\
\hline \multicolumn{4}{|l|}{ Risk factors } \\
\hline Diabetes mellitus & $11(13.9)$ & $2(5.4)$ & 0.220 \\
\hline Corticosteroids & $14(17.7)$ & $8(21.6)$ & 0.800 \\
\hline Smoking & $13(16.5)$ & $8(21.6)$ & 0.606 \\
\hline \multicolumn{4}{|l|}{ ASA-PS class } \\
\hline Median (range) & $2(1-4)$ & $3(1-4)$ & 0.172 \\
\hline Class 1 & $3(3.8)$ & $2(5.4)$ & \\
\hline Class 2 & $44(55.7)$ & $14(37.8)$ & \\
\hline Class 3 & $30(38.0)$ & $20(54.1)$ & \\
\hline Class 4 & $2(2.5)$ & $1(2.7)$ & \\
\hline \multicolumn{4}{|l|}{ Indication for surgery } \\
\hline Junctional location of the fracture & $36(45.6)$ & $12(32.4)$ & 0.226 \\
\hline Vertebra plana & $30(38.0)$ & $16(43.2)$ & 0.685 \\
\hline Fracture-related neurological deficit & $18(22.8)$ & $8(21.6)$ & $>0.999$ \\
\hline Fracture-related spinal stenosis from anterior & $59(74.7)$ & $19(51.4)$ & 0.019 \\
\hline OF score & $4(2-5)$ & $4(2-5)$ & 0.797 \\
\hline OF classification-based score (Blattert et al. $2018^{9}$ ) & $8(4-12)$ & $9(2-15)$ & 0.855 \\
\hline Postoperative inpatient $(\mathrm{d}$; mean $\pm \mathrm{SD}$; range) & $19.8 \pm 11.9(6-77)$ Median 16 & $14.9 \pm 12.4(2-53)$ Median 11 & 0.001 \\
\hline
\end{tabular}

It shows the patient data for patients undergoing $360^{\circ}$ instrumentation as well as only dorsal instrumentation including fracture-related data. Both cohorts show a similar distribution of risk factors including the ASA-PS (American Society of Anaesthesiologists physical status) class and classification of osteoporotic fractures (OF)

spine for cases with $360^{\circ}$ instrumentation, compared to $50 \%$ for cases with dorsal instrumentation, with $43.0 \%$ and $35.1 \%$ of surgeries performed percutaneously $(p=0.419$; Table 2$)$. Cement augmentation of screws was performed in $98.7 \%$ of cases with VBR compared to $94.6 \%$ of cases with dorsal instrumentation only ( $p=0.238$; Table 2$)$. Surgery was performed $3.7 \pm 3.7(0-15)$ days from admission for patients with $360^{\circ}$ instrumentation and $5.6 \pm 6.1(0-24)$ days from admission for patients with dorsal instrumentation.

\section{Clinical outcome}

Regarding patients with $360^{\circ}$ instrumentation, $59.5 \%$ of patients developed complications postoperatively, compared to $64.9 \%$ of patients who underwent only dorsal instrumentation ( $p=0.684$; Table 3$)$. Wound healing disorders including wound infections were reported in $12.7 \%$ of patients who underwent $360^{\circ}$ instrumentation and in $24.3 \%$ of patients with dorsal instrumentation $(p=0.176$; Table 3). Regarding permanent surgery-related neurological deficits persisting at the time of discharge, two patients in the group of dorsal instrumentation showed postoperative deterioration of motor function of the lower extremities due to secondary hemorrhage. For $360^{\circ}$ instrumentation, a permanent loss of bladder and bowel control occurred in one case after dorsal instrumentation due to persistent stenosis at the fractured level, which was still present at the follow-up examination. Further complications are listed in Table 3.

At the end of the study, a follow-up including quality of life (EQ-5D Germany) was obtained, which was completed by 79 patients ( 52 with VBR) after $4.00 \pm 2.88$ years (0.1-11.8 years). Follow-up was performed $3.70 \pm 2.45$ years (0.30-9.04) postoperatively for $360^{\circ}$ compared to $4.58 \pm 3.55$ years $(0.13-11.84)$ for dorsal instrumentation $(p=0.427$; Table 4$)$. Quality of life was $0.56 \pm 0.32$ $(-0.21-1.00)$ for patients with VBR compared to $0.56 \pm 0.34$ $(-0.08-1.00)$ of patients without VBR after dorsal instrumentation ( $p=0.994$; Table 4). Reoperation rates due to construct failure or adjacent segment degeneration in a longterm follow-up were low at $13.5 \%$ and $11.1 \%$ for cases with VBR and without VBR ( $p>0.999$; Table 4).

At the time of follow-up, opioids were taken by $29.6 \%$ of patients with dorsal instrumentation compared to $26.9 \%$ among patients after VBR $(p=0.797)$. Systemic osteoporosis medication was taken in $73.1 \%$ of patients after VBR compared to $51.9 \%$ in patients after dorsal instrumentation $(p=0.081)$. 
Table 2 Surgical data

\begin{tabular}{|c|c|c|c|}
\hline$n(\%)$ & $\begin{array}{l}360^{\circ} \\
\text { instrumentation }\end{array}$ & Dorsal instrumentation & $p$ value \\
\hline Number of fractures & 85 & 44 & - \\
\hline Operated levels (mean $\pm \mathrm{SD}$; range) & $4.6 \pm 2.2(2-18)$ & $4.6 \pm 1.8(2-10)$ & 0.449 \\
\hline Cement augmentation of screws & $78(98.7)$ & $35(94.6)$ & 0.238 \\
\hline Cement augmentation of fractured vertebra & - & $4(10.8)$ & - \\
\hline $\begin{array}{l}\text { Percutaneous } \\
\text { instrumentation }\end{array}$ & $34(43.0)$ & $13(35.1)$ & 0.419 \\
\hline \multicolumn{4}{|l|}{ Fractured segment } \\
\hline Thoracic fracture & $38(44.8)$ & $22(50.0)$ & n.s \\
\hline$T 4$ & $0(0.0)$ & $2(4.5)$ & \\
\hline$T 5$ & $0(0.0)$ & $1(2.3)$ & \\
\hline$T 6$ & $4(4.7)$ & $1(2.3)$ & \\
\hline$T 7$ & $2(2.4)$ & $2(4.5)$ & \\
\hline$T 8$ & $3(3.5)$ & $3(6.8)$ & \\
\hline$T 9$ & $4(4.7)$ & $2(4.5)$ & \\
\hline$T 10$ & $1(1.2)$ & $2(4.5)$ & \\
\hline$T 11$ & $5(5.9)$ & $2(4.5)$ & \\
\hline$T 12$ & $19(22.4)$ & $7(15.9)$ & \\
\hline Lumbar fracture & $47(55.2)$ & $22(50.0)$ & \\
\hline$L 1$ & $17(20.0)$ & $5(11.4)$ & \\
\hline$L 2$ & $12(14.1)$ & $2(4.5)$ & \\
\hline$L 3$ & $11(12.9)$ & $6(13.6)$ & \\
\hline$L 4$ & $4(4.7)$ & $4(9.1)$ & \\
\hline$L 5$ & $3(3.5)$ & $5(11.4)$ & \\
\hline
\end{tabular}

This table compares the surgical procedures regarding dorsal instrumentation for patients with and without additional vertebral body replacement. No significant differences were found between both cohorts

Table 3 Postoperative complications

\begin{tabular}{llll}
\hline$n(\%)$ & $360^{\circ}$ instrumentation & $\begin{array}{l}\text { Dorsal } \\
\text { instrumenta- } \\
\text { tion }\end{array}$ & $p$ value \\
\hline Overall & $47(59.5)$ & $24(64.9)$ & 0.684 \\
Systemic infections & $23(29.1)$ & $9(24.3)$ & 0.661 \\
$\begin{array}{l}\text { Wound healing } \\
\text { disorder/secondary }\end{array}$ & $10(3.8)$ & $9(24.3)$ & 0.176 \\
$\quad$ hemorrhage & & $3(8.1)$ & 0.382 \\
$\begin{array}{l}\text { Wound infections } \\
\text { Intensive care unit }\end{array}$ & $10(12.7)$ & & \\
$\begin{array}{l}\text { Permanent surgery- } \\
\text { related neurologi- }\end{array}$ & $1(1.3)$ & $6(16.2)$ & 0.579 \\
cal deficit & & $2(5.4)$ & 0.238 \\
\hline
\end{tabular}

This table lines up the rate of postoperative complications for both cohorts. All infections requiring systemic antibiotic treatment, excluding wound infections, were considered as systemic infections. Wound infects were listed separately in the group of wound healing disorders

\section{Radiological outcome}

For patients undergoing dorsal instrumentation followed by VBR, the correction of the angle of the fractured spine levels was $6.4 \pm 5.0^{\circ}\left(0.5-22.7^{\circ}\right)$ after dorsal instrumentation and increased to $9.3 \pm 7.4^{\circ}\left(0.1-31.6^{\circ}\right)$ after VBR (Fig. 2). For patients undergoing dorsal instrumentation only, a correction of $6.0 \pm 5.6^{\circ}\left(0.2-22.8^{\circ}\right)$ was achieved (Fig. 2). Correction after VBR was significantly higher $(p=0.0065)$ than correction in cases with dorsal instrumentation without VBR. The curvature correction at the fractured vertebral body for the thoracic spine was $6.4 \pm 6.3^{\circ}$ and $10.3 \pm 7.2^{\circ}$ (dorsal only vs. $360^{\circ} ; p=0.017$ ) and $5.6 \pm 4.9^{\circ}$ and $8.5 \pm 7.5^{\circ}$ (dorsal only vs. $360^{\circ} ; p=0.148$ ) for the lumbar spine. Cage subsidence on postoperative imaging occurred in 72 fractures (84.7\%) measuring $5.7 \pm 3.6(0-14) \mathrm{mm}$.

\section{Discussion}

Since 2018, the OF classification based on the work of the Spine Section of the DGOU has been introduced as a novel diagnostic tool [10]. The proposed OF classification served as an attempt to group the most common osteoporotic fracture types. According to this study, OF types 4 and 5 were declared as clear indications for surgical treatment [10]. OF type 3 fractures remained a debatable type, which might be treated surgically or conservatively [10]. OF type 
Table 4 Patient outcome

\begin{tabular}{lllc}
\hline$n(\%)$ & $360^{\circ}$ instrumentation & Dorsal instrumentation & $p$ value \\
\hline Number of patients & $52(65.8)$ & $27(73.0)$ & - \\
Time of follow-up (years; mean \pm SD; range) & $3.70 \pm 2.45$ & $4.58 \pm 3.55$ & 0.427 \\
& $(0.30-9.04)$ & $(0.13-11.84)$ & \\
EQ-5D Germany (mean \pm SD; range) & $0.56 \pm 0.32$ & $0.56 \pm 0.34$ & 0.994 \\
Reoperation rates & $(-0.21-1.00)$ & $(-0.08-1.00)$ & \\
Opioids & $7(13.5)$ & $3(11.1)$ & 0.999 \\
Systemic osteoporosis medication & $14(26.9)$ & $8(29.6)$ & 0.797 \\
\hline
\end{tabular}

It shows the long-term patient outcome including quality of life (EQ-5D Germany). Reoperation rates include failure of construct as well as adjacent segment degeneration

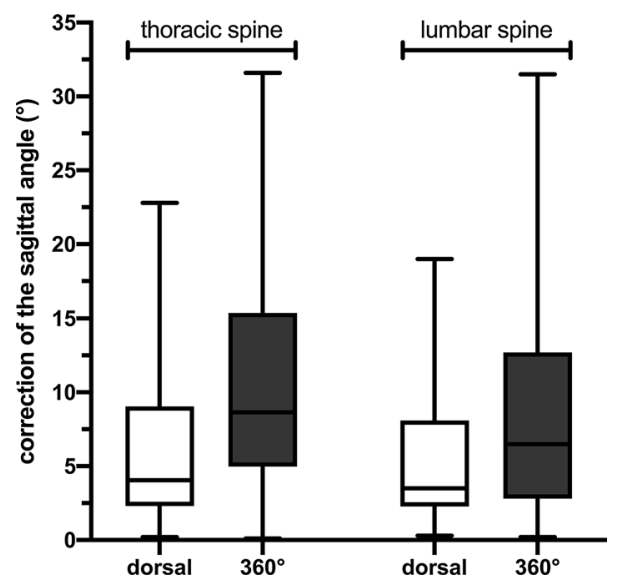

Fig. 2 Radiological outcome: Correction of the fracture-related sagittal angle. It shows the curvature correction at the fractured vertebral body for the thoracic (dorsal only vs. $360^{\circ} ; p=0.017$ ) and lumbar spine (dorsal only vs. $360^{\circ} ; p=0.148$ ) comparing patients undergoing dorsal instrumentation (dorsal) to patients with $360^{\circ}$ instrumentation $\left(360^{\circ}\right)$

1 and OF type 2 fractures were reported as indications for conservative treatment [10]. Together with this classification, the working group developed a score for therapeutic decision-making and proposed guidelines for treatment [12]. Alternative augmentative procedures for OF type 1 and 2 fractures like vertebroplasty or kyphoplasty have been further introduced [11]. In OF type 3, 4, and 5 fractures, dorsal instrumentation with or without vertebral body replacement or polymethyl methacrylate (PMMA) cement augmentation of the inserted pedicle screws was recommended [12]. Minimal invasive techniques like percutaneous instrumentation and hybrid monosegmental instrumentation combined with kypho- or vertebroplasty were favored especially in OF type 3 fractures [12]. The OF classification-based score by Blattert et al. further classified three groups based on fracture morphology (OF type), bone mineral density (BMD) and $T$-score, dynamics of the fracture process, pain score (visual analogue scale (VAS) score), associated neurological deficits, patient mobility, and general health status (ASA-PS class) [11]. However, this score does not include factors like fracture-related spinal stenosis from anterior or junctional location of the fracture, which are essential factors in surgical decision-making.

Our study was performed to analyze the clinical and radiological outcomes of patients with osteoporotic thoracolumbar fractures in a real-life setting in which other factors were revealed to influence surgical strategy considerably apart from the available literature. The indications for a staged approach in our study population originated from clinical presentation with new neurological deficits, major spinal stenosis from anterior, vertebra plana, or location of vertebral fracture in a junctional spinal segment (Table 1). Depending on the subjective opinion of the treating surgeon, additional VBR was performed or waived after dorsal instrumentation according to the above-mentioned arguments including neurological status of the patient postoperatively as well as intraoperative findings and correction of the sagittal angle on postoperative X-ray scans. By that, this series represents clinical reality very closely. Indications for the operative procedure were discussed at our neurosurgical department meeting. While surgical experience was persistent over recruitment time, there was a steady change in paradigm regarding more aggressive treatment strategies. Therefore, similar patients were treated differently over time resulting from clinical experience. This also accounts for the number of patients treated with percutaneous instrumentation, where there was a clear trend toward percutaneous instrumentation even in cases with additional decompression and cases of the upper thoracic spine.

In previous studies, experts advised a hybrid approach with kyphoplasty as anterior stabilization technique or less invasive techniques in the elderly population [13, 14]. Furthermore, authors reported beneficial results with a posterior approach only through short-segment fixation and postulated a safer way of treatment for patients at high surgical risk [15]. Our results do not justify this statement anymore. Particularly, kyphoplasty of the fractured vertebra cannot be regarded as any additional reinforcement in instrumented fractures. The intervertebral disks are still soft in many 
patients and allow for enough elasticity to cause screw loosening; at least kyphoplasty does not prevent this. Open ventral VBR, in contrast, provided reliable reinforcement, better curvature correction (Fig. 2), no risk of additional cement embolism, and the option of ventral decompression. Moreover, blood loss in VBR of osteoporotic fracture is minimal and not comparable to acute traumatic fractures of younger patients whose vertebra have a strong blood supply due to their bone marrow still being a major part of hematopoiesis. This is not the case in the elderly [16]. Complication rates in spinal surgery vary greatly between studies ranging from 17 to $52 \%$, identifying age over 65 years as a risk factor for increased complication rates [17-19]. Due to multimorbidity and high age, complications rates overall were expectedly high among patients in our study which is still in the usual international range if urinary tract infection and other minor events are included. However, patients undergoing $360^{\circ}$ instrumentation experienced complication rates comparable to those in patients treated solely with posterior instrumentation including rates of wound healing disorder, need for intensive care unit treatment, and rates of new postoperative neurological deficits (Table 3). In addition to that, high failure rates up to $24 \%$ due to bending or breaking of instrumentation have been reported with the use of short-segment fixation for thoracolumbar burst fractures, compared to an overall reoperation rate including adjacent segment degeneration and failure of construct of $13 \%$ in our study representing a more aggressive approach [20].

Long-segment fixations reduce the range of motion and improve the stiffness of constructs, which is essential in osteoporotic patients, especially in junctional segments like the thoracolumbar junction [21]. As for kyphotic deformity, previous studies found an involvement of thoracolumbar junction to be a risk factor for progressive kyphosis. This is due to the great static and dynamic load mainly applied on the anterior part of the vertebral body [8]. For patients with dorsal instrumentation, only a high rate of postoperative loss of correction with subsequent re-kyphosis was observed [22, 23].

For osteoporotic fractures of the vertebral body, it might also be relevant to reconstruct the sagittal profile; at least this is still unclear [24]. Patients with VBR showed a significantly better curvature correction in our series (Fig. 2). Whether this has any clinical benefit or implications cannot be proven in detail. However, there is a bias in the measurement of the sagittal profile as preoperative CT scans performed in all patients were compared to postoperative plain standing X-rays as preoperative plain standing X-rays were not possible due to pain, neurological deficits, or instability of the fracture in multiple cases. QoL, however, was comparable, nonetheless. Long-term patient outcome at followup via EQ-5D was identical in both groups $0.56 \pm 0.32$ vs $0.56 \pm 0.34(p=0.994)$.
Furthermore, data on the role of neurological deficits and fracture-related anterior spinal stenosis, where the possibility of additional anterior decompression might be of benefit, are still scarce. Kaneda et al. showed a favorable outcome in a study of 27 patients with traumatic burst fractures and neurological deficits treated by anterior decompression and instrumentation with complete neurologic recovery in $66.7 \%$ and no reported new postoperative deficit [25].

In biomechanical studies, combined instrumentations provided superior rigidity and reduced ROM in all directions compared to other types of instrumentations [26]. Knop et al. compared treatment strategies of traumatic injuries of the thoracolumbar spine, showing significantly higher correction rates of the fracture-related kyphotic deformity and a significantly lower relative loss of correction in the radiological follow-up examinations for cases with $360^{\circ}$ instrumentation [22]. Our study approves these findings, which are yet clinically irrelevant.

In this series, $360^{\circ}$ instrumentation was done via a staged surgical approach. According to this, we observed a prolonged hospital stay in patients with $360^{\circ}$ approach with an average of $19.8 \pm 11.9$ days (6-77) compared to $14.9 \pm 12.4$ days $(2-53)$ in the dorsal instrumentation group (Table 1), which is the time between the two surgeries and correlates with the current literature [27]. Besides implant costs, this longer stay further increases treatment costs compared to dorsal instrumentation only. If reoperation and thus cost reduction on long-term follow-up is achieved, $360^{\circ}$ instrumentation cannot be answered by this study.

\section{Conclusion}

To be clear, this is not a randomized trial and the overall question was not the comparison between posterior only and $360^{\circ}$ instrumentation as competing options. We rather intended to analyze clinical reality in a large spine center mirroring various surgical approaches of different surgeons as it is the case all over the world.

Our data confirm that $360^{\circ}$ instrumentation represents a legitimate surgical strategy if sufficient long-term construct stability is doubted by the treating surgeons or considerable ventral stenosis is present. If the treating team considers additional ventral reinforcement or decompression, such additional surgery provides no additional risk but balanced morbidity even for the elderly and multimorbid osteoporotic population. In our experience, especially percutaneous augmented dorsal instrumentation plus anterior spinal canal decompression and VBR provide a minimally invasive option if anterior spinal canal stenosis is present.

Supplementary Information The online version contains supplementary material available at https://doi.org/10.1007/s00586-021-07044-3. 
Acknowledgements $\mathrm{BM}$ received honoraria, consulting fees, and research grants from Medtronic (Meerbusch, Germany), Icotec AG (Altstätten, Switzerland), and Relievant Medsystems Inc., (Sunnyvale, CA, USA), honoraria and research grants from Ulrich Medical (Ulm, Germany), honoraria and consulting fees from Spineart Deutschland GmbH (Frankfurt, Germany) and DePuy Synthes (West Chester, PA, USA), and royalties from Spineart Deutschland GmbH (Frankfurt, Germany). SK is consultant for Ulrich Medical (Ulm, Germany) and Brainlab AG (Munich, Germany) and received honoraria from Nexstim Plc (Helsinki, Finland), Spineart Deutschland GmbH (Frankfurt, Germany), Medtronic (Meerbusch, Germany), and Carl Zeiss Meditec (Oberkochen, Germany). BM received research grants and is consultant for Brainlab AG (Munich, Germany).

Funding Open Access funding enabled and organized by Projekt DEAL. The authors did not receive support from any organization for the submitted work. No funding was received to assist with the preparation of this manuscript. No funding was received for conducting this study. No funds, grants, or other support was received. This study was funded entirely by institutional grants from the Department of Neurosurgery, Technical University of Munich, Germany, School of Medicine, Klinikum rechts der Isar.

\section{Declarations}

Conflict of interest All authors declare that they have no conflict of interest regarding the materials used or the results presented in this study. All authors declare no other relationships or activities that could appear to have influenced the submitted work.

Open Access This article is licensed under a Creative Commons Attribution 4.0 International License, which permits use, sharing, adaptation, distribution and reproduction in any medium or format, as long as you give appropriate credit to the original author(s) and the source, provide a link to the Creative Commons licence, and indicate if changes were made. The images or other third party material in this article are included in the article's Creative Commons licence, unless indicated otherwise in a credit line to the material. If material is not included in the article's Creative Commons licence and your intended use is not permitted by statutory regulation or exceeds the permitted use, you will need to obtain permission directly from the copyright holder. To view a copy of this licence, visit http://creativecommons.org/licenses/by/4.0/.

\section{References}

1. Curtis E, Litwic A, Cooper C, Dennison E (2015) Determinants of muscle and bone aging. J Cell Physiol 230:2618-2625. https:// doi.org/10.1002/jcp. 25001

2. Lane JM, Russell L, Khan SN (2000) Osteoporosis. Clin Orthop Relat Res. https://doi.org/10.1097/00003086-200003000-00016

3. Kado DM, Browner WS, Palermo L, Nevitt MC, Genant HK, Cummings SR (1999) Vertebral fractures and mortality in older women: a prospective study. Study of osteoporotic fractures research group. Arch Intern Med 159:1215-1220. https://doi.org/ 10.1001/archinte.159.11.1215

4. Hernlund E, Svedbom A, Ivergard M, Compston J, Cooper C, Stenmark J, McCloskey EV, Jonsson B, Kanis JA (2013) Osteoporosis in the European Union: medical management, epidemiology and economic burden. A report prepared in collaboration with the International Osteoporosis Foundation (IOF) and the European Federation of Pharmaceutical Industry Associations
(EFPIA). Arch Osteoporos 8:136. https://doi.org/10.1007/ s11657-013-0136-1

5. Ballane G, Cauley JA, Luckey MM, El-Hajj Fuleihan G (2017) Worldwide prevalence and incidence of osteoporotic vertebral fractures. Osteoporos Int 28:1531-1542. https://doi.org/10.1007/ s00198-017-3909-3

6. Rajasekaran S, Kanna RM, Schnake KJ, Vaccaro AR, Schroeder GD, Sadiqi S, Oner C (2017) Osteoporotic thoracolumbar fractures-how are they different?-classification and treatment algorithm. J Orthop Trauma 31(Suppl 4):S49-S56. https://doi.org/10. 1097/BOT.0000000000000949

7. Longo UG, Loppini M, Denaro L, Maffulli N, Denaro V (2012) Osteoporotic vertebral fractures: current concepts of conservative care. Br Med Bull 102:171-189. https://doi.org/10.1093/bmb/ ldr048

8. Muratore M, Ferrera A, Masse A, Bistolfi A (2018) Osteoporotic vertebral fractures: predictive factors for conservative treatment failure. A systematic review. Eur Spine J 27:2565-2576. https:// doi.org/10.1007/s00586-017-5340-Z

9. Ettinger B, Black DM, Nevitt MC, Rundle AC, Cauley JA, Cummings SR, Genant HK (1992) Contribution of vertebral deformities to chronic back pain and disability. The study of osteoporotic fractures research group. J Bone Miner Res 7:449-456. https:// doi.org/10.1002/jbmr.5650070413

10. Schnake KJ, Blattert TR, Hahn P, Franck A, Hartmann F, Ullrich B, Verheyden A, Mork S, Zimmermann V, Gonschorek O, Muller M, Katscher S, Saman AE, Pajenda G, Morrison R, Schinkel C, Piltz S, Partenheimer A, Muller CW, Gercek E, Scherer M, Bouzraki N, Kandziora F, Spine Section of the German Society for O, Trauma (2018) Classification of osteoporotic thoracolumbar spine fractures: recommendations of the spine section of the german society for orthopaedics and trauma (DGOU). Global Spine J 8:46S-49S. https://doi.org/10.1177/2192568217717972

11. Blattert TR, Schnake KJ, Gonschorek O, Gercek E, Hartmann F, Katscher S, Mork S, Morrison R, Muller M, Partenheimer A, Piltz S, Scherer MA, Ullrich BW, Verheyden A, Zimmermann V, Spine Section of the German Society for O, Trauma (2018) Nonsurgical and surgical management of osteoporotic vertebral body fractures: recommendations of the spine section of the german society for orthopaedics and trauma (DGOU). Global Spine J 8:50S-55S. https://doi.org/10.1177/2192568217745823

12. Schnake KJ, Bula P, Spiegl UJ, Muller M, Hartmann F, Ullrich BW, Blattert TR (2017) Thoracolumbar spinal fractures in the elderly : classification and treatment. Unfallchirurg 120:10711085. https://doi.org/10.1007/s00113-017-0435-x

13. Spiegl U, Jarvers JS, Heyde CE, Josten C (2017) Osteoporotic vertebral body fractures of the thoracolumbar spine: indications and techniques of a 360 degrees -stabilization. Eur J Trauma Emerg Surg 43:27-33. https://doi.org/10.1007/s00068-016-0751-9

14. Spiegl UJ, Anemuller C, Jarvers JS, von der Hoh N, Josten C, Heyde CE (2019) Hybrid stabilization of unstable osteoporotic thoracolumbar vertebral body fractures: clinical and radiological outcome after a mean of 4 years. Eur Spine J 28:1130-1137. https://doi.org/10.1007/s00586-019-05957-8

15. Lin CL, Chou PH, Fang JJ, Huang KY, Lin RM (2018) Short-segment decompression and fixation for thoracolumbar osteoporotic fractures with neurological deficits. J Int Med Res 46:3104-3113. https://doi.org/10.1177/0300060518772422

16. Griffith JF, Yeung DK, Tsang PH, Choi KC, Kwok TC, Ahuja AT, Leung KS, Leung PC (2008) Compromised bone marrow perfusion in osteoporosis. J Bone Miner Res 23:1068-1075. https://doi. org/10.1359/jbmr.080233

17. Campbell PG, Yadla S, Nasser R, Malone J, Maltenfort MG, Ratliff JK (2012) Patient comorbidity score predicting the incidence of perioperative complications: assessing the impact of 
comorbidities on complications in spine surgery. J Neurosurg Spine 16:37-43. https://doi.org/10.3171/2011.9.SPINE11283

18. Lee MJ, Konodi MA, Cizik AM, Bransford RJ, Bellabarba C, Chapman JR (2012) Risk factors for medical complication after spine surgery: a multivariate analysis of 1,591 patients. Spine J 12:197-206. https://doi.org/10.1016/j.spinee.2011.11.008

19. Reis RC, de Oliveira MF, Rotta JM, Botelho RV (2015) Risk of complications in spine surgery: a prospective study. Open Orthop J 9:20-25. https://doi.org/10.2174/1874325001509010020

20. Carl AL, Tromanhauser SG, Roger DJ (1992) Pedicle screw instrumentation for thoracolumbar burst fractures and fracturedislocations. Spine (Phila Pa 1976) 17:S317-324. https://doi.org/ 10.1097/00007632-199208001-00018

21. Wu Y, Chen CH, Tsuang FY, Lin YC, Chiang CJ, Kuo YJ (2019) The stability of long-segment and short-segment fixation for treating severe burst fractures at the thoracolumbar junction in osteoporotic bone: a finite element analysis. PLoS ONE 14:e0211676. https://doi.org/10.1371/journal.pone.0211676

22. Knop C, Blauth M, Buhren V, Arand M, Egbers HJ, Hax PM, Nothwang J, Oestern HJ, Pizanis A, Roth R, Weckbach A, Wentzensen A (2001) Surgical treatment of injuries of the thoracolumbar transition-3: follow-up examination. Results of a prospective multi-center study by the "Spinal" study group of the german society of trauma surgery. Unfallchirurg 104:583-600. https://doi. org/10.1007/s001130170089

23. Knop C, Bastian L, Lange U, Blauth M (1999) Transpedicular fusion of the thoraco-lumbar junction. Clinical, radiographic and
CT results. Orthopade 28:703-713. https://doi.org/10.1007/s0013 20050400

24. Dimar JR 2nd, Wilde PH, Glassman SD, Puno RM, Johnson JR (1996) Thoracolumbar burst fractures treated with combined anterior and posterior surgery. Am J Orthop (Belle Mead NJ) 25:159-165

25. Kaneda K, Abumi K, Fujiya M (1984) Burst fractures with neurologic deficits of the thoracolumbar-lumbar spine. Results of anterior decompression and stabilization with anterior instrumentation. Spine (Phila Pa 1976) 9:788-795. https://doi.org/10.1097/ 00007632-198411000-00004

26. Vahldiek M, Gosse F, Panjabi MM (2002) Stability of ventral, dorsal and combined spondylodesis in vertebral body prosthesis implantation. Orthopade 31:508-513. https://doi.org/10.1007/ s00132-001-0292-7

27. Ulmar B, Richter M, Kelsch G, Cakir B, Puhl W, Huch K (2005) Distractible vertebral body replacement for the thoracic and lumbar spine. Acta Orthop Belg 71:467-471

Publisher's Note Springer Nature remains neutral with regard to jurisdictional claims in published maps and institutional affiliations. 